\title{
Calcium to magnesium intake ratio and non-alcoholic fatty liver disease development: a case-control study
}

\author{
Hadi Emamat ${ }^{1}$, Hamid Ghalandari ${ }^{2}$, Ali Saneei Totmaj ${ }^{3}$, Hadith Tangestani ${ }^{4}$ and Azita Hekmatdoost ${ }^{*}$
}

\begin{abstract}
Background: Non-alcoholic fatty liver disease (NAFLD) is the most common chronic liver disease worldwide. Adoption of sedentary life style and westernized diet are shown to be associated with development of NAFLD. Since previous studies suggested that calcium (Ca) to magnesium ( $\mathrm{Mg}$ ) ratio intake is associated with some chronic diseases including dyslipidemia and insulin resistance, we designed this study to find any possible association between this ratio and NAFLD development.
\end{abstract}

Methods: The NAFLD was diagnosed using Fibroscan according to a CAP cut-off value of $263 \mathrm{~dB} / \mathrm{m}$. Dietary intakes of one hundred and ninety-six patients with incident NAFLD diagnosis, and eight hundred and three controls without NAFLD were assessed using a valid food frequency questionnaire (FFQ). Dietary nutrients were calculated using Nutritionist IV software.

Results: Age of the study population (57\% female) was $43.2 \pm 14.1$ years. In addition, energy-adjusted daily calcium to magnesium intake ratio was $2.34 \pm 0.57$ and $2.73 \pm 0.69$ for control and case groups, respectively. In the multivariable-adjusted model, after adjustment for potential confounding variables; including, age, gender, BMI, alcohol consumption, smoking, diabetes, physical activity, energy, dietary fiber, carbohydrate, fat, and protein intakes, participants in the third (Q3) and fourth (Q4) quartile of $\mathrm{Ca} / \mathrm{Mg}$ ratio intake had a greater development of incidental NAFLD compared to the lowest quartile (Q1) [(OR=2.86; $95 \% \mathrm{Cl}: 1.20-6.81)$, (P-value $=0.017)$ and $(\mathrm{OR}=$ 5.97; $95 \%$ Cl: 2.54-14.01), ( $P$-value < 0.001) for Q3 and Q4 compared to the Q1, respectively]. Moreover, energyadjusted Ca to Mg intake ratio was positively correlated with plasma level of ALT ( $r=0.18 ; P=0.01)$; contrarily, it had no correlation with plasma levels of AST.

Conclusions: The current study revealed that higher dietary Ca to Mg intake ratio is associated with a greater development of NAFLD. Further interventional studies are needed to confirm the causal relationship of the $\mathrm{Ca} / \mathrm{Mg}$ ratio intake and development of NAFLD.

\footnotetext{
* Correspondence: a_hekmat2000@yahoo.com

${ }^{2}$ Department of Clinical Nutrition and Dietetics, Faculty of Nutrition Sciences and Food Technology, National Nutrition and Food Technology Research Institute, ShahidBeheshti University of Medical Sciences, 19395 - 4741, No 7, West Arghavan St., Farahzadi Blvd, 1981619573 Tehran, Iran

Full list of author information is available at the end of the article
}

(C) The Author(s). 2021 Open Access This article is licensed under a Creative Commons Attribution 4.0 International License, which permits use, sharing, adaptation, distribution and reproduction in any medium or format, as long as you give appropriate credit to the original author(s) and the source, provide a link to the Creative Commons licence, and indicate if changes were made. The images or other third party material in this article are included in the article's Creative Commons licence, unless indicated otherwise in a credit line to the material. If material is not included in the article's Creative Commons licence and your intended use is not permitted by statutory regulation or exceeds the permitted use, you will need to obtain permission directly from the copyright holder. To view a copy of this licence, visit http://creativecommons.org/licenses/by/4.0/ The Creative Commons Public Domain Dedication waiver (http://creativecommons.org/publicdomain/zero/1.0/) applies to the data made available in this article, unless otherwise stated in a credit line to the data. 


\section{Background}

Non-alcoholic fatty liver disease (NAFLD) includes the entire spectrum of fatty liver disease in patients without significant alcohol consumption, ranging from fatty liver to steatohepatitis to cirrhosis [1]. NAFLD is one of the most common causes of liver cirrhosis and liver cancer [2-4]. The mortality rate of cirrhosis and cirrhosisrelated diseases such as liver cancer has increased over the past 35 years worldwide [5]. Obesity, type 2 diabetes, overmedication, and exposure to the toxic substances constitute the etiology of NAFLD [6-8]. Patients with metabolic syndrome are much more likely to develop NAFLD [9, 10].It has been estimated that NAFLD will be one of the leading causes of liver disease and its consequent mortality by 2030 , along with the obesity epidemic [11]. There is also a population so called "lean NAFLD" [12]. It has been shown that weight reduction is also beneficial in this population [13]. The first line in the treatment of NAFLD is dietary interventions and reducing central obesity [14]. Although the pathogenic role of macronutrients in NAFLD and obesity are clear, the contribution of micronutrients in the pathogenesis of NAFLD has garnered less attention than that of obesity [15]. Overall, micronutrients play an important role in NAFLD pathogenesis [16].

Magnesium $(\mathrm{Mg})$ is an abundant cation in the human body that plays essential roles in multiple physiological pathways such as cellular energy metabolism, inflammation, nucleic acid metabolism, protein synthesis, and electrolyte balance [17]. Serum $\mathrm{Mg}$ concentration is strictly controlled; however, hypomagnesemia may occur as a result of increased renal excretion or decreased digestive absorption of magnesium [18]. Hypomagnesemia and subclinical Mg deficiency are associated with osteoporosis, seizure, depression, diabetes mellitus, hypertension, dyslipidemia, and colorectal cancer [19-21]. On the other hand, an observational study found that higher intakes of $\mathrm{Mg}$ are associated with a lower development of NAFLD in young adults [22].

Calcium $(\mathrm{Ca})$ is another major mineral that is mainly deposited in bone and plays a key role in various biological processes [23]. Ca and Mg could be regarded as antagonist to each other in various biochemical pathways [24]. Studies show that altered serum calcium is associated with dyslipidemia and insulin resistance [25]. Previous studies on human subjects indicate that a high $\mathrm{Ca}$ intake may affect the absorption rate of $\mathrm{Mg}$, which in turn, can be associated with an increased risk of several diseases [26-29]. Taking all these facts into account, it is plausible to consider the intake ratio of calcium to magnesium as a potential contributor to NAFLD pathogenesis [28].

Due to the novelty of the idea, we decided to examine the possible relationship between calcium to magnesium intake ratio and development of NAFLD in this study.

\section{Materials/subjects and methods}

This case-control study was conducted at two clinics in Tehran province of Iran. The study included 196 cases with NAFLD and 803 controls. These participants were selected with the convenience sampling procedure. We conducted this case-control study on patients with recently diagnosed NAFLD and age-matched controls subjects from the same clinic. The absence of hepatic steatosis in individuals in the control group was determined using the ultrasound exam. The presence of NAFLD in our cases was confirmed by a gastroenterologist; moreover, the inclusion criteria included having a Controlled Attenuation Parameter (CAP) score of more than 263, fibrosis score more than 7 , determined by the Fibroscan device, and the intake of alcohol less than 20 gram/day in women, and less than 30 gram/day in men. Fibroscan is an ultrasound device calibrated to measure hepatic steatosis levels producing an index called CAP; CAP score indicates the level of infiltration of fat in hepatocytes and has sensitivity and specificity ranged between 78 and $100 \%$ [30]. All tests were performed by one operator with Fibroscan (EchoSens, Paris, France) device. Patients fasted for at least $3 \mathrm{~h}$ before the test. Patients were lying on the bed for at least 3 min before the test. The probes were calibrated before starting work. The other secondary causes of hepatic fat accumulation such as long-term use of a steatogenic medication (e.g., mipomersen, lomitapide, amiodarone, methotrexate, tamoxifen, corticosteroids, valproate and anti-retroviral medicines), or Hepatitis C (genotype 3) or Wilson disease or lipodystrophy or starvation or abetalipoproteinemia or Reye syndrome or inborn errors of metabolism were our exclusion criteria [1].

A validated food frequency questionnaire (FFQ) was used to assess the dietary intake of the participants [31]. Additionally, calorie-density of the two minerals (the amount of each mineral in an energy intake of 1000 Kcals) and their ratio were calculated for further analysis.

Baseline characteristics of all participants, including data on age, employment, marital status, education, smoking, past medical history, current use of medications and other factors were obtained by the interviewers. Physical activity level was assessed using physical activity questionnaire and was later quantified as metabolic equivalent hours per week (METs h/wk). Observational studies were reported according to STROBE guidelines.

Baseline characteristics and dietary intakes between two study groups were compared using student $\mathrm{t}$-test for continuous variables and chi-square for categorical variables.We used SPSS (Version 21.0; Chicago, IL, USA) software to conduct the satatistical analyses. The study participants were divided into four categories based 
onquartiles of daily energy-adjusted calcium to magnesium ratio and the lowest quartile was set as the reference category in order to evaluate the association between energy-adjusted daily calcium to magnesium intake ratio and NAFLD development. We took advantage of ANOVA test to compare the inter-quartile relationships. Odds ratios (ORs) and $95 \%$ confidence intervals (CIs) were calculated using multiple logistic regression analysis. Analyses were adjusted for all known confounding factors. P-value less than 0.05 considered as significant.

\section{Results}

Baseline participants' characteristics in case and control group are shown in Table 1. The participants in case group had higher levels of BMI, fasting blood sugar (FBS), triglyceride (TG), low-density lipoprotein-cholesterol (LDL-c), physical activity (PA), alanine aminotransferase (ALT), aspartate aminotransferase (AST), smoking, diabetes, male, protein, calcium and calcium to magnesium intake ratio and lower levels of high-density lipoprotein-cholesterol (HDL-c), carbohydrate and fat intake $(\mathrm{P}<0.05)$. Baseline characteristics regarding energy-adjusted daily calcium to magnesium intake ratio quartiles are presented in Table 2. Mean \pm SD age of the study population ( $57 \%$ female) was $43.2 \pm 14.1$ years. In addition, mean \pm SD of energy-adjusted daily calcium to magnesium intake ratio was $2.34 \pm 0.57$ and $2.73 \pm 0.69$ for control and case groups, respectively.

Inter-quartile analyses revealed that participants with higher daily calcium to magnesium intake ratio had significantly higher prevalence of smoking $(P<0.001)$, higher levels of BMI $(P=0.006)$, and higher levels of LDL-c $(P=0.033)$ compared to those with lower daily calcium to magnesium intake ratio. Significant differences were also detected regarding dietary intakes of energy $(P=0.024)$, carbohydrate $(\mathrm{P}<0.025)$, fat $(P=0.042)$, and dietary fiber $(P=0.001)$ when inter-quartile data were analyzed. Compared by the same criteria, no other statistically significant differences were found.

Firstly, we evaluated the associations of energy adjusted calcium and magnesium intake with the development of NAFLD (Tables 3 and 4). Regarding to the energy adjusted calcium intake, in the final model adjustments for potential confounding variables; including, age, gender, BMI, alcohol consumption, smoking,

Table 1 Baseline participants' characteristics in case and control group

\begin{tabular}{|c|c|c|c|}
\hline Characteristics & $\begin{array}{l}\text { Case } \\
(n=196)\end{array}$ & $\begin{array}{l}\text { Control } \\
(n=803)\end{array}$ & $P$ value ${ }^{*}$ \\
\hline Age (years) & $42.3 \pm 11.9$ & $43.5 \pm 14.5$ & 0.214 \\
\hline Male (\%) & 51.5 & 41.0 & 0.007 \\
\hline Body mass index $\left(\mathrm{kg} / \mathrm{m}^{2}\right)$ & $35.7 \pm 10.6$ & $27.7 \pm 4.5$ & $<0.001$ \\
\hline Fasting blood glucose (mg/dl) & $108.5 \pm 37.6$ & $90.2 \pm 29.4$ & $<0.001$ \\
\hline Triglycerides (mg/dl) & $176.0 \pm 117.9$ & $132.0 \pm 81.8$ & $<0.001$ \\
\hline Total cholesterol (mg/dl) & $185.7 \pm 52.8$ & $177.5 \pm 38.9$ & 0.118 \\
\hline High Density Lipoprotein-Cholesterol (mg/dl) & $41.9 \pm 16.1$ & $47.7 \pm 10.5$ & 0.001 \\
\hline Low Density Lipoprotein-Cholesterol(mg/dl) & $120.9 \pm 41.6$ & $104.0 \pm 31.9$ & $<0.001$ \\
\hline Physical activity (MET(hour/week)) & $31.0 \pm 3.2$ & $34.2 \pm 3.1$ & $<0.001$ \\
\hline Alanine aminotransferase $(U / L)$ & $55.71 \pm 8.27$ & $20.49 \pm 7.59$ & $<0.001$ \\
\hline Aspartate aminotransferase $(\mathrm{U} / \mathrm{L})$ & $33.86 \pm 23.69$ & $22.14 \pm 7.72$ & $<0.001$ \\
\hline Current alcohol usage (\%) & 12.8 & 9.1 & 0.07 \\
\hline Current smoking (\%) & 89.7 & 18.8 & $<0.001$ \\
\hline Diabetes (\%) & 16.6 & 6.8 & $<0.001$ \\
\hline Energy (Kcal/d) & $2757 \pm 961.1$ & $2804 \pm 840.7$ & 0.499 \\
\hline Protein (\% of energy) & $15.8 \pm 2.9$ & $14.1 \pm 2.3$ & $<0.001$ \\
\hline Carbohydrate (\% of energy) & $58.2 \pm 6.3$ & $59.8 \pm 13.3$ & 0.014 \\
\hline Fat (\% of energy) & $29.2 \pm 5.3$ & $33.8 \pm 5.7$ & $<0.001$ \\
\hline Total dietary fiber $(\mathrm{g} / \mathrm{d})$ & $46.29 \pm 19.07$ & $55.69 \pm 46.11$ & 0.08 \\
\hline Magnesium (mg/d) & $484 \pm 155$ & $509 \pm 173$ & 0.09 \\
\hline Calcium (mg/d) & $1389 \pm 458$ & $1114 \pm 390$ & $<0.001$ \\
\hline Calcium to Magnesium ratio & $2.79 \pm 0.68$ & $2.34 \pm 0.57$ & $<0.001$ \\
\hline
\end{tabular}

Quantitative data are presented as mean \pm SD and qualitative data reported as percent

*Independent sample t-test and chi-square or Fisher exact test for quantitative and qualitative parameters, respectively 
Table 2 Baseline participants'characteristics across quartiles of energy-adjusted daily calcium to magnesium ratio intake

\begin{tabular}{|c|c|c|c|c|c|}
\hline \multirow[b]{2}{*}{ Characteristics } & \multicolumn{5}{|c|}{ Quartiles of energy-adjusted daily calcium to magnesium ratio intake } \\
\hline & Q1 $(n=250)$ & Q2 $(n=249)$ & Q3 $(n=250)$ & Q4 $(n=250)$ & $P$ value $^{*}$ \\
\hline Age (years) & $45.1 \pm 13.7$ & $41.9 \pm 14.3$ & $43.5 \pm 14.1$ & $43.3 \pm 14.3$ & 0.16 \\
\hline Male (\%) & 42.4 & 45 & 46.8 & 38 & 0.21 \\
\hline Body mass index $\left(\mathrm{kg} / \mathrm{m}^{2}\right)$ & $28.7 \pm 5.2$ & $27.8 \pm 5.3$ & $28.4 \pm 5.8$ & $29.1 \pm 6.7$ & 0.006 \\
\hline Fasting blood glucose (mg/dl) & $94.4 \pm 34.6$ & $92.9 \pm 34.1$ & $89.8 \pm 30$ & $92.3 \pm 27.1$ & 0.44 \\
\hline Triglycerides (mg/dl) & $139 \pm 92.1$ & $140 \pm 109.6$ & $133 \pm 71.9$ & $131 \pm 67.9$ & 0.69 \\
\hline Total cholesterol (mg/dl) & $179 \pm 36.3$ & $178 \pm 44.4$ & $175 \pm 33.9$ & $183 \pm 37.1$ & 0.33 \\
\hline $\begin{array}{l}\text { High Density Lipoprotein-Cholesterol } \\
(\mathrm{mg} / \mathrm{dl})\end{array}$ & $46.7 \pm 10.2$ & $46.4 \pm 11.2$ & $47.2 \pm 10.3$ & $49.1 \pm 11.8$ & 0.44 \\
\hline $\begin{array}{l}\text { Low Density Lipoprotein-Cholesterol } \\
\text { (mg/dl) }\end{array}$ & $104 \pm 30.7$ & $103 \pm 35.6$ & $101 \pm 29.6$ & $107 \pm 29.5$ & 0.033 \\
\hline Physical activity (MET(hour/week)) & $32.1 \pm 4.4$ & $34.9 \pm 3.3$ & $31 \pm 3.9$ & $33.8 \pm 2.1$ & 0.22 \\
\hline Alanine aminotransferase (U/L) & $22.9 \pm 23.1$ & $23.7 \pm 28.6$ & $24.2 \pm 14.1$ & $23.4 \pm 19.1$ & 0.08 \\
\hline Aspartate aminotransferase (U/L) & $23.1 \pm 10.3$ & $23.6 \pm 13.6$ & $23.5 \pm 9.2$ & $22.1 \pm 8.9$ & 0.95 \\
\hline Current alcohol usage (\%) & 9.6 & 10.4 & 9.2 & 10 & 0.97 \\
\hline Current smoking (\%) & 25.6 & 32.1 & 28.8 & 44.2 & $<0.001$ \\
\hline Diabetes (\%) & 10.8 & 7.6 & 7.6 & 8.9 & 0.53 \\
\hline Energy (Kcal/d) & $2712 \pm 857$ & $2846 \pm 815$ & $2876 \pm 930$ & $2758 \pm 769$ & 0.024 \\
\hline Protein (\% of energy) & $14.8 \pm 1.5$ & $14.4 \pm 3.3$ & $15.1 \pm 1.7$ & $14.9 \pm 6.3$ & 0.16 \\
\hline Carbohydrate (\% of energy) & $58.6 \pm 12.3$ & $56.8 \pm 10.9$ & $54.9 \pm 8.2$ & $59.1 \pm 8.7$ & 0.025 \\
\hline Fat (\% of energy) & $29.4 \pm 1.3$ & $32.5 \pm 2.1$ & $30.9 \pm 7.6$ & $29.1 \pm 4.2$ & 0.042 \\
\hline Total dietary fiber (g/d) & $43.6 \pm 16$ & $45.4 \pm 17.6$ & $50.1 \pm 36.8$ & $50.1 \pm 21.1$ & 0.001 \\
\hline Magnesium (mg/d) & $521 \pm 178$ & $508 \pm 154$ & $491 \pm 167$ & $434 \pm 130$ & $<0.001$ \\
\hline Calcium (mg/d) & $879 \pm 315$ & $1106 \pm 340$ & $1249 \pm 419$ & $1404 \pm 412$ & $<0.001$ \\
\hline Calcium to Magnesium ratio & $1.69 \pm 0.20$ & $2.17 \pm 0.11$ & $2.54 \pm 0.12$ & $3.25 \pm 0.38$ & $<0.001$ \\
\hline
\end{tabular}

Quantitative data are presented as mean \pm SD and qualitative data reported as percent

*one way ANOVA test and chi-square or Fisher exact test for quantitative and qualitative parameters, respectively

Table 3 The development of non- alcoholic fatty liver disease across quartiles of energy-adjusted daily calcium intake

\begin{tabular}{|c|c|c|c|c|c|c|c|}
\hline & \multicolumn{7}{|c|}{ Energy-adjusted daily calcium intake } \\
\hline & $\mathrm{Q} 1(n=249)$ & Q2(n= 250) & $P$-value ${ }^{*}$ & $\mathrm{Q} 3(n=250)$ & $P$-value & $Q 4(n=250)$ & $P$-value ${ }^{*}$ \\
\hline Cases/control & $18 / 231$ & $25 / 225$ & & $49 / 201$ & & $104 / 146$ & \\
\hline $\begin{array}{l}\text { Range of energy- } \\
\text { adjusted Ca }\end{array}$ & 135.8 to 347.3 & 347.7 to 407.3 & & 407.4 to 473.4 & & 473.9 to 1034.2 & \\
\hline aModel 1 & 1 (Ref) & $\begin{array}{l}1.42 \\
(0.75-2.68)\end{array}$ & 0.27 & $\begin{array}{l}3.12 \\
(1.76-5.54)\end{array}$ & $<0.001$ & $\begin{array}{l}9.14 \\
(5.31-15.71)\end{array}$ & $<0.001$ \\
\hline${ }^{\mathrm{b}}$ Model 2 & 1 (Ref) & $\begin{array}{l}1.43 \\
(0.75-2.70)\end{array}$ & 0.28 & $\begin{array}{l}3.34 \\
(1.87-5.96)\end{array}$ & $<0.001$ & $\begin{array}{l}9.96 \\
(5.73-17.33)\end{array}$ & $<0.001$ \\
\hline 'Model 3 & 1 (Ref) & $\begin{array}{l}1.92 \\
(0.81-4.54)\end{array}$ & 0.13 & $\begin{array}{l}2.81 \\
(1.70-6.51)\end{array}$ & 0.001 & $\begin{array}{l}6.34 \\
(3.05-10.39)\end{array}$ & $<0.001$ \\
\hline 'Model 4 & 1 (Ref) & $\begin{array}{l}1.99 \\
(0.76-5.17)\end{array}$ & 0.15 & $\begin{array}{l}3.03 \\
(1.25-7.36)\end{array}$ & 0.014 & $\begin{array}{l}5.41 \\
(3.87-10.87)\end{array}$ & $<0.001$ \\
\hline
\end{tabular}

Data are presented as odds ratio $(95 \% \mathrm{Cl})$

*Logistic regression

${ }^{a}$ crude model

${ }^{\mathrm{b}}$ Adjusted for age and gender

'Additionally adjusted for body mass index, alcohol consumption, smoking, diabetes and physical activity

${ }^{\mathrm{d}}$ Additionally adjusted for energy, dietary fiber, carbohydrate, fat, and protein intakes

The significance level: $P<0.05$ 
Table 4 The development of non- alcoholic fatty liver disease across quartiles of energy-adjusted daily magnesium intake

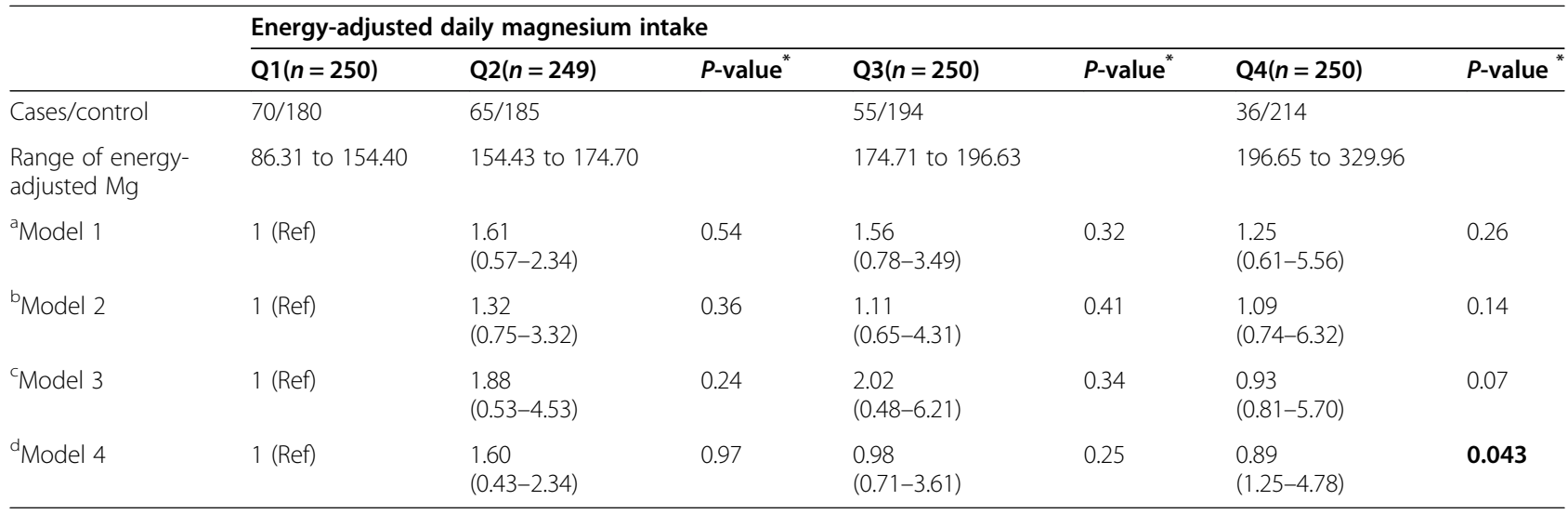

Data are presented as odds ratio $(95 \% \mathrm{Cl})$

"Logistic regression

${ }^{a}$ crude model

${ }^{\mathrm{b}}$ Adjusted for age and gender

${ }^{\mathrm{C}}$ Additionally adjusted for body mass index, alcohol consumption, smoking, diabetes and physical activity

${ }^{\mathrm{d}}$ Additionally adjusted for energy, dietary fiber, carbohydrate, fat, and protein intakes

The significance level: $P<0.05$

diabetes, physical activity, energy, dietary fiber, carbohydrate, fat, and protein intakes, a positive association was detected between dietary calcium intake and the development of NAFLD in the third (Q3) and fourth (Q4) quartile compared to the lowest quartile (Q1) $[(\mathrm{OR}=$ 3.03; $95 \%$ CI: $1.25-7.36),(P$-value $=0.014)$ and $(\mathrm{OR}=$ 5.41; $95 \%$ CI: $3.87-10.87),(P$-value $<0.001)$ for Q3 and Q4 compared to the Q1, respectively] (Table 3). However, analyzes showed a negative association between the energy adjusted dietary magnesium intake and the development of NAFLD in fourth (Q4) quartile compared to the lowest quartile $(\mathrm{Q} 1) \quad[(\mathrm{OR}=0.89 ; 95 \% \mathrm{CI}$ : $1.25-$ $4.78),(P$-value $=0.043)]($ Table 4$)$.
The data regarding the association between energyadjusted calcium to magnesium intake ratio and the development of NAFLD is presented in Table 5. In the crude model, a positive association was detected between dietary calcium to magnesium intake ratio and the development of NAFLD in the third (Q3) and fourth (Q4) quartile compared to the lowest quartile (Q1) $[(\mathrm{OR}=2.01 ; 95 \% \mathrm{CI}: 1.21-3.34), \quad(P$-value $=0.007)$ and $(\mathrm{OR}=4.33$; $95 \% \mathrm{CI}: 2.68-6.97),(P$-value $<0.001)$ for $\mathrm{Q} 3$ and Q4compared to the Q1, respectively].In the multivariable-adjusted model, after adjustment for potential confounding variables; including, age, gender, BMI, alcohol consumption, smoking, diabetes, physical

Table 5 The development of non- alcoholic fatty liver disease across quartiles of energy-adjusted daily calcium to magnesium ratio intake

\begin{tabular}{|c|c|c|c|c|c|c|c|}
\hline & \multicolumn{7}{|c|}{ Energy-adjusted daily calcium to magnesium ratio intake } \\
\hline & $\mathrm{Q1}(n=250)$ & $\mathrm{Q} 2(n=249)$ & $P$-value ${ }^{*}$ & Q3(n=250) & $P$-value ${ }^{*}$ & $\mathrm{Q} 4(n=250)$ & $P$-value ${ }^{*}$ \\
\hline Cases/control & $27 / 223$ & $34 / 215$ & & $49 / 201$ & & $86 / 164$ & \\
\hline Range of Ca to $\mathrm{Mg}$ ratio & 0.95 to 1.97 & 1.97 to 2.36 & & 2.36 to 2.81 & & 2.82 to 5.02 & \\
\hline aModel 1 & 1 (Ref) & $\begin{array}{l}1.30 \\
(0.76-2.23)\end{array}$ & 0.33 & $\begin{array}{l}2.01 \\
(1.21-3.34)\end{array}$ & 0.007 & $\begin{array}{l}4.33 \\
(2.68-6.97)\end{array}$ & $<0.001$ \\
\hline${ }^{\mathrm{b}}$ Model 2 & 1 (Ref) & $\begin{array}{l}1.22 \\
(0.71-2.11)\end{array}$ & 0.46 & $\begin{array}{l}1.93 \\
(1.15-3.21)\end{array}$ & 0.012 & $\begin{array}{l}4.45 \\
(2.75-7.21)\end{array}$ & $<0.001$ \\
\hline${ }^{\mathrm{c}}$ Model 3 & 1 (Ref) & $\begin{array}{l}1.57 \\
(0.73-3.35)\end{array}$ & 0.24 & $\begin{array}{l}2.89 \\
(1.35-6.16)\end{array}$ & 0.006 & $\begin{array}{l}5.72 \\
(2.82-11.60)\end{array}$ & $<0.001$ \\
\hline dModel 4 & 1 (Ref) & $\begin{array}{l}1.82 \\
(0.76-4.37)\end{array}$ & 0.17 & $\begin{array}{l}2.86 \\
(1.20-6.81)\end{array}$ & 0.017 & $\begin{array}{l}5.97 \\
(2.54-14.01)\end{array}$ & $<0.001$ \\
\hline
\end{tabular}

Data are presented as odds ratio $(95 \% \mathrm{Cl})$

*Logistic regression

${ }^{a}$ crude model

${ }^{\mathrm{b}}$ Adjusted for age and gender

'Additionally adjusted for body mass index, alcohol consumption, smoking, diabetes and physical activity

${ }^{\mathrm{d}}$ Additionally adjusted for energy, dietary fiber, carbohydrate, fat, and protein intakes

The significance level: $P<0.05$ 
activity, energy, dietary fiber, carbohydrate, fat, and protein intakes, participants in the third (Q3) and fourth (Q4) quartile had a greater development of incidental NAFLD compared to the lowest quartile (Q1) $[(\mathrm{OR}=$ 2.86; $95 \%$ CI: $1.20-6.81),(P$-value $=0.017)$ and $(\mathrm{OR}=$ 5.97; $95 \%$ CI: 2.54-14.01), ( $P$-value $<0.001)$ for Q3 and $\mathrm{Q} 4$ compared to the Q1, respectively].

To investigate the relationship between the energyadjusted calcium to magnesium intake ratio and plasma levels of alanine aminotransferase (ALT) and aspartate aminotransferase (AST), the Pearson correlation test was conducted. Energy-adjusted calcium to magnesium intake ratio was positively correlated with plasma level of ALT $(r=0.18 ; P=0.01)$; contrarily, it had no correlation with plasma levels of AST.

\section{Discussion}

In this case control study, we observed that subjects with higher energy-adjusted dietary calcium to magnesium intake ratio had a greater development for incidental NAFLD, independent of confounding factors including age, gender, BMI, alcohol consumption, smoking, diabetes, physical activity, energy, dietary fiber, carbohydrate, fat, and protein intakes.

Recent studies have shown that the impact of nutritional factors on the incidence of NAFLD is more pronounced [32-35]. To the best of our knowledge, there is no study that has examined the relationship between the calcium to magnesium intake ratio and the development of NAFLD; however, calcium and magnesium were separately investigated as potential mediators in the pathogenesis of the disease. Based on consistent evidence, intake of magnesium was inversely associated to the factors related to the risk of insulin resistance [36], and metabolic syndrome, specifically factors such as high fasting glucose level, high waist circumference, and low high-density lipoprotein cholesterol [37, 38]. Lu et al. found that higher intakes of $\mathrm{Mg}$ during adulthood is related to a lower risk of NAFLD in middle age [22]. Moreover, in another study, subjects with NAFLD or alcoholic fatty liver were at higher risk of developing magnesium deficiency [39]. However, another study conducted in Canada was not able to find any links between magnesium intake and risk of NAFLD; considering the structural weaknesses in this study, the results might lack enough credibility to be deductible [40].

As mentioned beforehand in the present article, calcium has some biochemical interactions with magnesium. These interactions might have clinical manifestations concerning the pathogenesis of several metabolic disorders. Wenshuai $\mathrm{Li}$ et al. who investigated the data related to the Third National Health and Nutrition Examination Survey (NHANES III) follow-up US adults' cohort [41], found out that the intake of magnesium was associated to an approximately $30 \%$ reduced risk of NAFLD and prediabetes, only in subjects who consumed less than $1200 \mathrm{mg} /$ day calcium. Their findings suggested that beneficial effect of magnesium might be attenuated when calcium intake is higher than the amount recommended by Dietary Reference Intakes (DRIs). One of the important mechanisms might be the suppressive effects of high calcium intake on the gastrointestinal absorption and renal reabsorption of magnesium which may alter the excretion of the ion in the feces and urine [24, 42].

As evident by the results of the present study, the Ca: $\mathrm{Mg}$ intake ratio might be a useful indicator to observe the combined impact of these two major minerals may exert upon different physiologic, as well as pathologic pathways. USDA food surveys from 1977 to 2007-8 show a rising food $\mathrm{Ca}: \mathrm{Mg}$ ratio from 2.3 to 2.9 to $2.9-3.5$ for all USA adults; these figures might be worthy of concern as they coincide with the rise of several metabolic diseases such as diabetes and colorectal cancer [43]. Furthermore, there is growing evidence indicating that modifications in serum $\mathrm{Ca}: \mathrm{Mg}$ ratio is associated with some disorders including diabetes and metabolic syndrome [44], breast cancer [45, 46], cardiovascular diseases [47], and higher mortality [29]. Even though the optimal calcium to magnesium intake ratio is yet to be specified, some studies have suggested a 2:1 ratio as the optimum ratio [47]. Consistent with previous studies, our study indicated that participants in the third and fourth quartiles of Ca:Mg intake ratio (ranging from 2.36 to 5.02) had a significantly higher risk of NAFLD as compared to the first quartile.

The regulation of calcium and magnesium homeostasis in the body is interdependent. Calcium-sensitive receptor, also known as CaSR, is responsible to monitor plasma levels of both cations [48].Whenever the plasma level of each of the cations drops, CaSR up regulates the related mechanisms leading to an increase in its blood level, regardless of the other cation concentration in the blood $[49,50]$. Furthermore, a drop in serum Mg could also decrease intracellular levels of $\mathrm{Mg}$ reducing the cellular Mg-ATP deposits. This may lead to an increase in $\mathrm{Ca}$ influx, which, in turn, may upgrade the $\mathrm{Ca}-\mathrm{ATP}$ level of the cell. Increased intracellular calcium levels have been proposed an underlying mechanism for the pathogenesis of several metabolic and inflammatory disorders such as obesity, metabolic syndrome, diabetes, and NAFLD [45, 51-53].

This is the first observational study that evaluated the relationship between $\mathrm{Ca}: \mathrm{Mg}$ intake ratio and the development of NAFLD. We were able to conduct the present research on a statistically acceptable sample size of subjects with corresponding socio-economic status. Moreover, the use of top-notch devices to determine the presence or the lack of the disease improved the 
accuracy and the precision of our inclusion/exclusion criteria. The present study also has some limitations. Case-control studies may prove an association but they do not demonstrate causation. Proving the causal relationship requires future intervention studies. Although we used a validated FFQ for measurement of dietary intakes, recall bias and measurement error are inevitable errors. Furthermore, although we tried to control the effect of major confounding factors, the effects of unknown factors and residual confounding cannot be ruled out. We also suggest that liver stiffness measurement (LSM) by Fibroscan be used in future studies for accurate prediction of liver fibrosis severity. Calculation of Fibrosis-4 (FIB-4) or NAFLD fibrosis score (NFS) which are indicators of advanced fibrosis in NAFLD patients used in exclusion of advanced fibrosis owing to its high negative predictive value is also recommended [54-56].

\section{Conclusions}

The current study revealed that higher dietary calcium to magnesium intake ratio is associated with a greater development of NAFLD. Further interventional studies are needed to confirm the causal relationship between the dietary calcium to magnesium intake ratio and incidental NAFLD.

\section{Abbreviations}

NAFLD: Non-alcoholic fatty liver disease; CAP: Controlled Attenuation Parameter; FFQ: Food frequency questionnaire; MET: Metabolic equivalent; BMI: Body mass index; HDL-c: High density lipoprotein; FBS: Fasting blood sugar; TG: Triglycerides; LDL-c: Low-density lipoprotein; PA: Physical activity; AST: Aspartate aminotransferase; ALT: Alanine aminotransferase; CaSR: Calcium-sensitive receptor

\section{Acknowledgements}

We also appreciate the "Student Research Committee" and "Research \& Technology Chancellor" in Shahid Beheshti University of Medical Sciences for their financial support of this study.

\section{Authors' contributions}

A.H. and H.E. conceptualized the study, collected the data, and wrote the manuscript. H. Gh., A.S.T. and H.T. analyzed the data and contributed to drafting of the manuscript. A.H supervised the study.All authors approved the final version of the manuscript.

\section{Funding}

This study is related to the project NO: 1398/10129 from the Student Research Committee, Shahid Beheshti University of Medical Sciences (SBMU), Tehran, Iran.

\section{Availability of data and materials}

The datasets used and/or analysed during the current study are available from the corresponding author on reasonable request.

\section{Declarations}

\section{Ethics approval and consent to participate}

The study protocol was approved by the ethics committee of the Shahid Beheshti University of medical sciences (ethical code: IR.SBMU.RETECH.REC.1398.568). Written informed consent was signed by all subjects participated.

\section{Consent for publication}

Written consent for publication obtained from all participants.

\section{Competing interests}

The authors report no conflict of interest.

\section{Author details}

${ }^{1}$ Student Research Committee, Department of Clinical Nutrition and Dietetics, Faculty of Nutrition Sciences and Food Technology, National Nutrition and Food Technology Research Institute, Shahid Beheshti University of Medical Sciences, Tehran, Iran. ${ }^{2}$ Department of Clinical Nutrition and Dietetics, Faculty of Nutrition Sciences and Food Technology, National Nutrition and Food Technology Research Institute, ShahidBeheshti University of Medical Sciences, 19395 - 4741, No 7, West Arghavan St., Farahzadi Blvd, 1981619573 Tehran, Iran. ${ }^{3}$ Department of nutrition, School of Public Health, Iran University of Medical Sciences, Tehran, Iran. ${ }^{4}$ Department of Nutrition, Persian Gulf Tropical Medicine Research Center, Bushehr University of Medical Sciences, Bushehr, Iran.

Received: 3 November 2020 Accepted: 15 March 2021

Published online: 18 March 2021

\section{References}

1. Chalasani N, Younossi Z: The diagnosis and management of nonalcoholic fatty liver disease: Practice guidance from the American Association for the Study of Liver Diseases. 2018, 67:328-357.

2. Blachier M, Leleu H, Peck-Radosavljevic M, Valla D-C, Roudot-Thoraval F. The burden of liver disease in Europe: a review of available epidemiological data. Journal of hepatology. 2013;58:593-608.

3. Bedogni G, Nobili V, Tiribelli C. Epidemiology of fatty liver: an update. World journal of gastroenterology: WJG. 2014;20:9050.

4. Ding W, Fan J, Qin J. Association between nonalcoholic fatty liver disease and colorectal adenoma: a systematic review and meta-analysis. International Journal of Clinical and Experimental Medicine. 2015;8:322.

5. Wang $\mathrm{H}$, Naghavi M, Allen C, Barber RM, Bhutta ZA, Carter A, Casey DC, Charlson FJ, Chen AZ, Coates MM. Global, regional, and national life expectancy, all-cause mortality, and cause-specific mortality for 249 causes of death, 1980-2015: a systematic analysis for the Global Burden of Disease Study 2015. The lancet. 2016;388:1459-544.

6. Chang $Y$, Jung H-S, Cho J, Zhang Y, Yun KE, Lazo M, Pastor-Barriuso R, Ahn J, Kim C-W, Rampal S. Metabolically healthy obesity and the development of nonalcoholic fatty liver disease. American Journal of Gastroenterology. 2016;111:1133-40.

7. Fierbinteanu-Braticevici C, Sinescu C, Moldoveanu A, Petrisor A, Diaconu S, Cretoiu D, Braticevici B. Nonalcoholic fatty liver disease: one entity, multiple impacts on liver health. Cell biology and toxicology. 2017;33:5-14

8. Godos J, Federico A, Dallio M, Scazzina F: Mediterranean diet and nonalcoholic fatty liver disease: Molecular mechanisms of protection. International journal of food sciences and nutrition 2017, 68:18-27.

9. Chan WK, Tan ATB, Vethakkan SR, Tah PC, Vijayananthan A, Goh KL: Nonalcoholic fatty liver disease in diabetics-prevalence and predictive factors in a multiracial hospital clinic population in M alaysia. Journal of gastroenterology and hepatology 2013, 28:1375-1383.

10. Liangpunsakul S, Chalasani N: Unexplained elevations in alanine aminotransferase in individuals with the metabolic syndrome: results from the third National Health and Nutrition Survey (NHANES III). The American journal of the medical sciences 2005, 329:111-116.

11. Fleischman MW, Budoff M, Zeb I, Li D, Foster T: NAFLD prevalence differs among hispanic subgroups: the Multi-Ethnic Study of Atherosclerosis. World journal of gastroenterology: WJG 2014, 20:4987.

12. Akyuz U, Yesil A, Yilmaz Y: Characterization of lean patients with nonalcoholic fatty liver disease: potential role of high hemoglobin levels. Scand J Gastroenterol 2015, 50:341-346.

13. Hamurcu Varol P, Kaya E, Alphan E, Yilmaz Y: Role of intensive dietary and lifestyle interventions in the treatment of lean nonalcoholic fatty liver disease patients. Eur J Gastroenterol Hepatol 2020, 32:1352-1357.

14. Nascimbeni F, Pais R, Bellentani S, Day CP, Ratziu V, Loria P, Lonardo A: From NAFLD in clinical practice to answers from guidelines. Journal of hepatology 2013, 59:859-871.

15. García OP, Long KZ, Rosado JL: Impact of micronutrient deficiencies on obesity. Nutrition reviews 2009, 67:559-572. 
16. Pickett-Blakely O, Young K, Carr RM: Micronutrients in nonalcoholic fatty liver disease pathogenesis. Cellular and Molecular Gastroenterology and Hepatology 2018, 6:451-462.

17. Musso CG: Magnesium metabolism in health and disease. International urology and nephrology 2009, 41:357-362.

18. Quamme GA: Recent developments in intestinal magnesium absorption. Current opinion in gastroenterology 2008, 24:230-235.

19. Guerrero-Romero F, Rodriguez-Moran M: Low serum magnesium levels and metabolic syndrome. Acta diabetologica 2002, 39:209-213.

20. Sarrafzadegan N, Khosravi-Boroujeni H, Lotfizadeh M, Pourmogaddas A, Salehi-Abargouei A: Magnesium status and the metabolic syndrome: A systematic review and meta-analysis. Nutrition 2016, 32:409-417.

21. Touyz RM: Magnesium in clinical medicine. Front Biosci 2004, 9:1278-1293.

22. Lu L, Chen C, Li Y, Vanwagner L, Guo W, Zhang S, Shikany J, He K: Magnesium Intake Is Inversely Associated with the Risk of Non-Alcoholic Fatty Liver Disease Among American Young adults. Current Developments in Nutrition 2020, 4:1446-1446.

23. Moe SM: Disorders involving calcium, phosphorus, and magnesium. Primary Care: Clinics in Office Practice 2008, 35:215-237.

24. Hoenderop JG, Bindels RJ: Epithelial Ca2 + and Mg2 + channels in health and disease. Journal of the American Society of Nephrology 2005, 16:15-26.

25. Kim MK, Kim G, Jang EH, Kwon HS, Baek KH, Oh KW, Lee JH, Yoon K-H, Lee WC, Lee KW: Altered calcium homeostasis is correlated with the presence of metabolic syndrome and diabetes in middle-aged and elderly Korean subjects: the Chungju Metabolic Disease Cohort study (CMC study). Atherosclerosis 2010, 212:674-681.

26. Dai Q, Cantwell MM, Murray LJ, Zheng W, Anderson LA, Coleman HG: Dietary magnesium, calcium: magnesium ratio and risk of reflux oesophagitis, Barrett's oesophagus and oesophageal adenocarcinoma: a population-based case-control study. British Journal of Nutrition 2016, 115: 342-350.

27. Dai Q, Sandler RS, Barry EL, Summers RW, Grau MV, Baron JA: Calcium, magnesium, and colorectal cancer. Epidemiology (Cambridge, Mass) 2012, 23: 504.

28. Dai Q, Shrubsole MJ, Ness RM, Schlundt D, Cai Q, Smalley WE, Li M, Shyr Y, Zheng $\mathrm{W}$ : The relation of magnesium and calcium intakes and a genetic polymorphism in the magnesium transporter to colorectal neoplasia risk. The American journal of clinical nutrition 2007, 86:743-751.

29. Dai Q, Shu X-O, Deng X, Xiang Y-B, Li H, Yang G, Shrubsole MJ, Ji B, Cai H, Chow W-H: Modifying effect of calcium/magnesium intake ratio and mortality: a population-based cohort study. BMJ open 2013, 3.

30. Sasso M, Miette V, Sandrin L, Beaugrand M: The controlled attenuation parameter (CAP): a novel tool for the non-invasive evaluation of steatosis using Fibroscan. Clin Res Hepatol Gastroenterol 2012, 36:13-20.

31. Esfahani FH, Asghari G, Mirmiran P, Azizi F: Reproducibility and relative validity of food group intake in a food frequency questionnaire developed for the Tehran Lipid and Glucose Study. Journal of epidemiology 2010, 20: 150-158.

32. Asbaghi O, Emamat $H$, Kelishadi MR, Hekmatdoost A: The Association between Nuts Intake and Non-Alcoholic Fatty Liver Disease (NAFLD) Risk: a Case-Control Study. Clinical Nutrition Research 2020, 9:195.

33. Emamat H, Farhadnejad H, Movahedian M, Tangestani H, Mirmiran P, Hekmatdoost A: Dietary sodium intake in relation to non-alcoholic fatty liver disease risk: a case-control study. Nutrition \& Food Science 2020.

34. Emamat $H$, Farhadnejad $H$, Tangestani $H$, Totmaj AS, Poustchi $H_{\text {, }}$ Hekmatdoost A: Association of allium vegetables intake and non-alcoholic fatty liver disease risk. Nutrition \& Food Science 2020.

35. Emamat $H$, Foroughi $F$, Eini-Zinab $H$, Hekmatdoost $A$ : The effects of onion consumption on prevention of nonalcoholic fatty liver disease. Indian Journal of Clinical Biochemistry 2018, 33:75-80.

36. Cahill F, Shahidi M, Shea J, Wadden D, Gulliver W, Randell E, Vasdev S, Sun G: High dietary magnesium intake is associated with low insulin resistance in the Newfoundland population. Plos one 2013, 8:e58278.

37. Dibaba D, Xun P, Fly A, Yokota K, He K: Dietary magnesium intake and risk of metabolic syndrome: a meta-analysis. Diabetic Medicine 2014, 31:1301-1309.

38. He K, Liu K, Daviglus ML, Morris SJ, Loria CM, Van Horn L, Jacobs Jr DR, Savage PJ: Magnesium intake and incidence of metabolic syndrome among young adults. Circulation 2006, 113:1675-1682.

39. Turecky L, Kupcova V, Szantova M, Uhlikova E, Viktorinova A, Czirfusz A: Serum magnesium levels in patients with alcoholic and non-alcoholic fatty liver. Bratislavské lekárske listy 2006, 107:58.
40. Da Silva HE, Arendt BM, Noureldin SA, Therapondos G, Guindi M, Allard JP A cross-sectional study assessing dietary intake and physical activity in Canadian patients with nonalcoholic fatty liver disease vs healthy controls. Journal of the Academy of Nutrition and Dietetics 2014, 114:1181-1194.

41. Li W, Zhu X, Song Y, Fan L, Wu L, Kabagambe EK, Hou L, Shrubsole MJ, Liu J, Dai Q: Intakes of magnesium, calcium and risk of fatty liver disease and prediabetes. Public health nutrition 2018, 21:2088-2095.

42. Green J, Booth C, Bunning R: Acute effect of high-calcium milk with or without additional magnesium, or calcium phosphate on parathyroid hormone and biochemical markers of bone resorption. European journal of clinical nutrition 2003, 57:61-68.

43. Rosanoff A: Rising Ca:Mg intake ratio from food in USA Adults: a concern?Magnes Res 2010, 23:S181-193.

44. Moore LC: Calcium, Magnesium, and the Metabolic Syndrome in the 20012010 NHANES Adult Data Using Regression and Structural Equation Modeling Methods. Case Western Reserve University, 2015.

45. Sahmoun AE, Singh BB: Does a higher ratio of serum calcium to magnesium increase the risk for postmenopausal breast cancer?Medical hypotheses 2010, 75:315-318.

46. Tao M-H, Dai Q, Millen AE, Nie J, Edge SB, Trevisan M, Shields PG, Freudenheim JL: Associations of intakes of magnesium and calcium and survival among women with breast cancer: results from Western New York Exposures and Breast Cancer (WEB) Study. American Journal of Cancer Research 2016, 6:105.

47. Rowe WJ: Calcium-magnesium-ratio intake and cardiovascular risk. The American journal of cardiology 2006, 98:140-140.

48. Brown EM, MacLeod RJ: Extracellular calcium sensing and extracellular calcium signaling. Physiological reviews 2001, 81:239-297.

49. Hardwick LL, Jones MR, Brautbar N, Lee DB: Magnesium absorption: mechanisms and the influence of vitamin D, calcium and phosphate. The Journal of nutrition 1991, 121:13-23.

50. Norman D, Fordtran J, Brinkley LJ, Zerwekh J, Nicar M, Strowig S, Pak C: Jejunal and ileal adaptation to alterations in dietary calcium: changes in calcium and magnesium absorption and pathogenetic role of parathyroid hormone and 1,25-dihydroxyvitamin D. The Journal of clinical investigation 1981, 67:1599-1603.

51. Bartlett PJ, Gaspers LD, Pierobon N, Thomas AP: Calcium-dependent regulation of glucose homeostasis in the liver. Cell Calcium 2014, 55:306-316.

52. Arruda AP, Hotamisligil GS: Calcium homeostasis and organelle function in the pathogenesis of obesity and diabetes. Cell metabolism 2015, 22:381-397.

53. Oliva-Vilarnau N, Hankeova S, Vorrink SU, Mkrtchian S, Andersson ER, Lauschke VM: Calcium Signaling in Liver Injury and Regeneration. Frontiers in Medicine 2018, 5.

54. Kaya E, Bakir A: Simple Noninvasive Scores Are Clinically Useful to Exclude, Not Predict, Advanced Fibrosis: A Study in Turkish Patients with BiopsyProven Nonalcoholic Fatty Liver Disease. 2020, 14:486-491.

55. Alkayyali T, Qutranji L, Kaya E, Bakir A, Yilmaz Y: Clinical utility of noninvasive scores in assessing advanced hepatic fibrosis in patients with type 2 diabetes mellitus: a study in biopsy-proven non-alcoholic fatty liver disease. 2020, 57:613-618.

56. Kaya E, Bakir A, Eren F, Yilmaz Y: The utility of noninvasive scores in nonalcoholic fatty liver disease patients with normal and elevated serum transaminases. In Hepatology Forum. 2020: 8.

\section{Publisher's Note}

Springer Nature remains neutral with regard to jurisdictional claims in published maps and institutional affiliations.

\section{Ready to submit your research? Choose BMC and benefit from:}

- fast, convenient online submission

- thorough peer review by experienced researchers in your field

- rapid publication on acceptance

- support for research data, including large and complex data types

- gold Open Access which fosters wider collaboration and increased citations

- maximum visibility for your research: over $100 \mathrm{M}$ website views per year

At $\mathrm{BMC}$, research is always in progress.

Learn more biomedcentral.com/submissions 